\title{
Computer Aided Innovation - State of the Art from a New Product Development Perspective
}

\author{
Stefan Hüsig \\ Management of Innovation and Technology \\ University of Regensburg; 93040 Regensburg; Germany \\ Tel.: +49 (0)941 943-3228; Fax: +49 (0)941 943-3230 \\ Email: stefan.huesig@wiwi.uni-regensburg.de
}

\section{Stefan Kohn}

WHU - Otto Beisheim School of Management;

Burgplatz 2; 56179 Vallendar; Germany

Email: stefan.kohn@fuzzyfrontend.de

\section{Working Paper Status}

Published in Computers in Industry 60 (2009) 551-562 


\title{
Computer Aided Innovation - State of the Art from a New Product Development Perspective
}

\begin{abstract}
In this paper we present the state of the art in the field of Computer Aided Innovation (CAI) from a New Product Development (NPD) perspective. Based on a holistic understanding of the innovation process and its support by ICT, we provide an overview of the emerging issue of CAI in the NPD field. In particular, the latest research on the concept of CAI, its categorisation, potential benefits of CAI, trends in the CAI supply, and issues of CAI usage and implementation are discussed and summarized in this article. Current publications indicate that the emerging field of CAI has recently been getting more attention in the NPD area, but this research needs to integrate further the insights from other research areas in the CAI field. It must also make a better distinction between generic ICT and CAI to achieve a more specific and holistic perspective on CAI in the future.
\end{abstract}

Keywords: computer aided innovation, new product development

\section{Introduction}

That innovation is fundamental to the development of society, business rejuvenation and growth and critical to company survival in the long run is conventional wisdom that is hardly challenged by anyone in academia, politics or the business world. It is also acknowledged that innovation is more than invention or new products but a complex and multi-dimensional concept, which should be seen from different perspectives in its specific context [1] [2] [3]. Innovation can therefore arise in connection with any object, such as technologies, structures, markets, culture, strategies, systems, products, services or anything else man-made, and needs to be perceived as a difference concerning the qualitative newness [3]. The process of innovation is typically iterative, interactive, context-specific, multi-tasking, uncertain, path-dependent and the result of a new combination of ends and means. However, the key question remains how to accomplish this complex and at times chaotic process from ideation to market diffusion successfully. This was and is the starting point where practitioners and scholars from different disciplines like management, engineering and information systems work to improve the likelihood of success, efficiency and time to market of the new product development (NPD) process. With new or improved tools (e.g. CAD, CAE, CAM, etc.), methods (e.g. TRIZ, QFD, FMEA, etc.), process models (Stage-Gate systems, Concurrent Engineering, etc.) and other organisational or technological innovations, much progress has been made to improve the innovation capabilities of firms and to reduce the development times of new products significantly [4] [5] [6] [7] [8].

In this paper we highlight the role of information technologies in NPD, since increased attention has been given to the use of ICT support in this context [9] [10] [11] [12] [13] [14] [15] [16] [5] [17] [18] [19] [20] [21] [22] [23] [24] [25] [26] [7] [27]. Since ICT support has led to significant improvement in other business processes, there has been increasing interest in software support for the NPD process. Computeraided tools like CAD became generally accepted as efficiency enhancing in the development process and their utilization is expected to become a commodity among the majority of the large companies in the developed world. Therefore, specific software and tools to support the other innovation activities are seen as supportive to streamline the NPD process further and guide the project teams through the different information-generating and disseminating activities [19] [20]. Nevertheless, to many firms software support in the innovation process is still mainly focused on the technological activities with specific technically oriented CAx technologies or generic, simple and ubiquitous productivity and communication tools such as e-mail, Microsoft Office, and Excel/Access databases rather than more sophisticated and more complex tools [9] [28] [19] [20].

In the early creative phases and in the business activities of the NPD process, standard office tools are often used as the sole software support [29] [9] [30]. This gap in the ICT support is the application area of the growing field of Computer Aided Innovation (CAI), which is the emerging term for software support in the innovation process that does not focus solely on the subsequent construction and design oriented, technological NPD activities [20] [21] [31]. CAI is also seen as a young domain in the array of CAx technologies from an engineering perspective [31]. 
Although arising from the invention stage in the front end of the NPD process, a comprehensive vision conceives CAI systems that integrate the full innovation process holistically. The final goal of CAI is therefore to support firms throughout the entire innovation process and integrate other ICT systems and firm processes. Yet there is an ongoing discussion of the theoretical and empirical conceptualisation of the CAI term [20]. This discussion will be highlighted in the next section, followed by a summary of the potential benefits of CAI and major trends in the CAI supply identified so far. In this paper we also provide an overview of emerging issues in the CAI field such as CAI usage and implementation, and of the co-evolution of CAI and NPD systems in maturity models. We complete the paper with conclusions and implications for future research in CAI from a NPD perspective.

\section{Emergence, Concepts and Categories of CAI}

\subsection{Emergence, Development Trajectories and Concepts of CAI}

Overall, limited understanding about what kind of IT systems fall under the term CAI and what kind of benefits they can provide means that transparency and communication in the market for CAI products and the further development of more sophisticated tools still suffers. Historically speaking, CAI emerged from software tools which supported the use of Altschuller's TRIZ method [32] [33]. TRIZ, the SovietInitiated Theory of Inventive Problem Solving (“Теория решения изобретательских задач”), is gaining acknowledgement both as a systematic methodology for innovation and as a powerful tool for technology forecasting [34] [33]. From this perspective, CAI has mainly been related to software tools like Innovation Work Bench (Ideation International Inc.) or Tech Optimizer (Invention Machine) [32]. These products emerged in the USA in the early nineties and started a wave of software-supported invention methodologies which became increasingly sophisticated over time.

Other innovation theories such as Synectics, Mind Mapping, Brain Storming, or Lateral Thinking have also been implemented in software tools. This development was started from the very beginning of the innovation process; and from an engineering perspective, related the ICT support of these NPD activities to other CAx technologies [31]. However, this is not the sole source of the CAI concept and ICT support in this context. A technical analysis of the state of the art in ICT regarding the support of the front end of the innovation process by Nyffenegger [22] reveals that various technological development trajectories are applicable in NPD activities such as workflow, document and data management software, groupware and other generic tools and technologies.

From this information systems perspective, Management and Marketing Information Systems (MIS/MAIS), Decision Support Systems (DSS), and Group Decision Support Systems (GDSS) have been developed to support innovation activities more specifically [13] [16] [18] [19] [20] [35] [8]. Especially in the area of Enterprise Resource Planning (ERP) and Product Life Cycle Management (PLM) tools, a reverse development from the back to the front end of the innovation process can be observed. Since PLM tools are being integrated with knowledge and project management methods and tools, new alternatives arise which stem more from an information systems and business perspective. Specific patent management software and strategic planning tools for the NPD process add to the growing complexity of the CAI field [19] [20]. To add to this clouded picture, all development trajectories seem to strive for greater integration with their neighbouring application and tool areas so that the borders of these development domains might become more blurred in the future. Therefore, a theoretical or empirical conceptualisation of the CAI term is difficult but urgently needed to integrate these emerging perspectives on CAI. So far there is little understanding as to what is precisely meant by CAI, what kind of products are included in this term and which are excluded. This discussion is ongoing and needs to be understood better theoretically and empirically, even if CAI merges into one holistic system to support the innovation process, as some maturity models would suggest [10].

\subsection{Categories and Application Fields of CAI}

An initial step to build a categorization scheme to enhance transparency in the field of CAI and to lay a foundation for further research was provided by Kohn and Hüsig [20]. Based on a comprehensive market study to analyse over 150 currently available off-the-shelf CAI products, an initial categorization scheme for CAI was proposed. While the study cannot claim completeness, it provides a good market overview of 
the available solutions in the field of CAI. There is no clear categorisation of CAI available to date: there is no directory or catalogue that summarizes the current market offerings. The working definition for this survey included all non-private off-the-shelf tools that were used by professionals from different industries in at least one part of the innovation process but excluded company or industry specific and generic office products that were not specifically developed for the support of NPD. After a rigorous analysis process, 115 CAI products were categorized in different areas.

Typically CAI products range from simple applications for special aspects of the innovation process to comprehensive solutions suitable to support the whole innovation process from idea generation to product launch. An application-based categorisation scheme was used to enhance the transparency and clarity of the CAI definition. This categorisation consists of three main categories which represent important fields of activities in the innovation process and are supported frequently by current CAI tools. First, there is a category labelled "Strategy Management". The products in this group have in common that they help innovation managers to deal with strategic issues like portfolio or scenario management. Another prominent category is called "Idea Management". These products manage the front end of the innovation process from idea generation to idea collection to idea evaluation. The third and last category deals with the important issue of "Patent Management". The role of patents in the NPD process is twofold. First, patents can be used to protect inventions, and second, and at least equally important, patents can be used to stimulate inventions. Invention methodologies like TRIZ are based on patent data, for example. The management of patent information is therefore closely linked to innovation activities. Some products cover aspects of at least two of the major categories and are labelled "Holistic Solutions". This view links the CAI categorisation scheme of Kohn and Hüsig [20] with the maturity model of Bowden [10], since it aims at the level of integration of the CAI tools. The integrated fields of activities in the NPD process can be subdivided further, which provides a deeper understanding of the CAI functions. Therefore, the main categories are broken down into sub-items. Figure 1 shows a graphical representation of this categorization scheme.

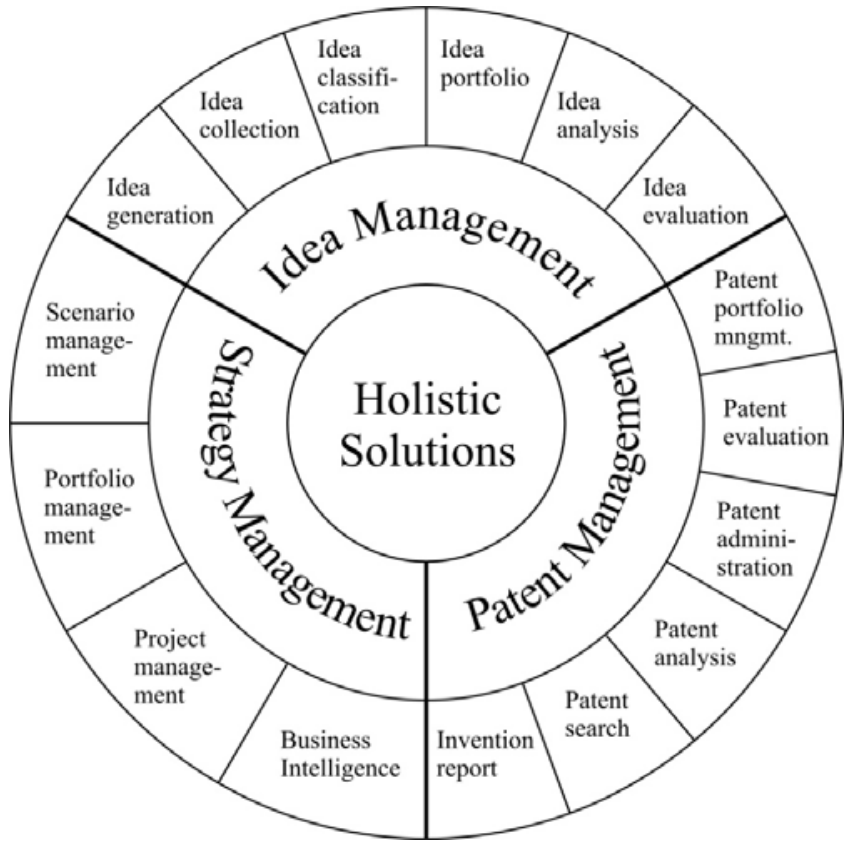

Figure 1: Innovation Circle: Detailed CAI Software Categories (Kohn and Hüsig, 2007).

The strategy management tools can be divided into several sub-categories. The tools researched typically offer support with different methodologies relevant to innovation, such as scenario management, portfolio management and project management.

- The first category consists of business intelligence tools that help the gathering and storing of relevant information on a broad basis. The field of idea management can be broken down into six sub-categories. Products for idea generation are mainly tools with an implemented creativity or similar idea generation technique. Brainstorming, TRIZ and mind mapping tools dominate this category.

- The second category contains tools for idea collection. These are mostly intranet-based database systems with the primary aim of enhancing process efficiency. 
- The third category is made up of idea classification tools that help cluster the ideas collected. This category is similar to the products that group ideas in an idea portfolio. The portfolio tools normally offer more sophisticated options to visualize the ideas. In contrast to the strategy, portfolio tools the products in this section normally follow a stage-gate process and offer different portfolios for the different stages of the projects in order to visualize the whole NPD pipeline.

- The fourth category helps the analysis of ideas. These tools help the gathering and storing of relevant data.

- The final category contains idea evaluation tools that frequently provide special checklists and sometimes have a built-in expert system to rate ideas. This last category, patent management, can be split into six sub-categories. These categories follow the standard patent management process. First, there are tools that support process efficiency when employees want to report an invention. Second, a broad range of tools were identified that help users to access (mainly free of charge) databases in order to perform patent searches. Once interesting patents have been identified they have to be analysed - which is the third category. Supporting the documentation and administration (e.g., the payment of the annual fees) of the patents from invention report to filing to licensing is the task of tools from the patent administration category. In order to manage a patent portfolio better they need to be regularly evaluated - which is methodologically supported by the patent evaluation tools. This input can be used in the last category of portfolio management.

Kohn and Hüsig [20] concluded that these categories would represent a holistic and comprehensive understanding of the term CAI. This categorisation scheme in fact improves transparency of the CAI market supply and helps to support the clarification of the term CAI, whose definition is still fuzzy. However, this approach needs to be developed further since the CAI field is in a constant state of flux and this framework is no more than a snapshot of the current situation. Additionally, other streams of CAI might be underrepresented in this categorisation scheme, such as other CAx technologies or PLM tools which might be integrated or subdivided more in the CAI field. At that point a need for even more integrated and holistic understanding of the term CAI might provide further sub-categories or enhance the comprehensiveness of future frameworks and CAI definitions.

\section{Categories and Elements of Potential Benefits of CAI}

This section provides an overview of the most significant potential benefits of CAI which are described in the academic literature so far. With a better understanding of the benefits and categories of CAI products the communication with potential users can be improved and directions for future development supported. If all necessary requirements are considered, the potential benefits of CAI products can be categorized as follows: efficiency, effectiveness, competence and creativity enhancing [19] [20]. These categories of potential benefits of CAI are elaborated in the following sub-sections.

\subsection{Efficiency Enhancing}

The main potential for efficiency can be found in the information and decision-making processes. One key to efficiency is the fast gathering and diffusion of relevant information and knowledge in NPD projects. Typically, software tools facilitate the integration, modification and transfer of data and information more than non-computer-aided methods. A highly skilled work force can be freed from routine work by delegating it to less expensive colleagues. The input of data and information needs to be done only once. If integrated and centralized, the information is easier to update and is consistently and ubiquitously accessible, which potentially lowers the transaction costs and saves search time. If all information is stored digitally, the danger of disruptions in the media flow might be reduced and transmission errors are easier to avoid. Furthermore, the speed and scope of transmission might be greater. Many CAI tools also offer functions to automate the generation of reports, documentations or analysis, which increases the productivity of the user. Moreover, CAI products can support standardized decision procedures and decision gates which help to structure the NPD process efficiently.

\subsection{Effectiveness Enhancing}

The resources that can be spent on the innovation process are limited. Consequently, less promising ideas have to be filtered out as early as possible; in contrast, the gates in the innovation process must be permeable enough to avoid dissipation of promising opportunities. Making the right decisions as early as possible in the innovation process is a key success factor for overall NPD success. CAI has the potential 
to enhance decision making by improving the quality, accuracy and timeliness of the information provided. Different scenarios and more alternatives can be considered, which improves the richness of the information as well as the rationality of the decisions and further reduces uncertainty [36]. CAI support is suitable for making these decision processes more effective and understandable if conjointly defined criteria are implemented. Rangaswamy and Lilien [24] identify promising opportunities of CAI support in the field of benchmarking alternative NPD projects. Moreover, more advanced methods for evaluating and analysing technological, competitor or customer information are facilitated by software support. Better management tools and methods - that rely on CAI support - might improve the quality of product concepts and business plans by reducing complexity [28] [37] [38].

Another aspect that enhances effectiveness is the capacity of several CAI tools to aggregate, structure and visualize information, which contributes to the reduced complexity and clarity of large amounts of information. A recent empirical study by Barczak et al [9] supports the effectiveness-enhancing effect of CAI since they even showed a direct, positive and significant influence on the commercial performance of the new products in the marketplace.

\subsection{Competence Enhancing}

The use of CAI software can support the transparency of processes. Thus innovation processes become more understandable and accepted within the firm. Additionally, knowledge about innovation and management methodology within CAI suppliers can be transferred to the users. The implemented knowledge of many CAI-supported methods enables less proficient customers to apply more sophisticated methodology with less effort. Some methodologies like complex scenario studies rely on the use of dedicated software products to accumulate the collected data and perform the sometimes-complex calculations necessary. Characteristically, the knowledge transfer is permanent since updates and new versions provide the latest advances in the specific knowledge area and foster individual and organizational learning. Recently, the integration of customers into the front end of the NPD process and co-operative innovation processes by specific ICT support have also been receiving more attention [39]. In this context, innovation-specific tools are developed for certain tasks which customers will fulfil during the front end of the NPD process and enhance the knowledge base through early interaction with customers and hence the market orientation and potential success in the NPD.

\subsection{Creativity Enhancing}

Creativity is a key to innovation success. The front end of the NPD process in particular depends on the creation of new ideas. While the later stages are mainly characterized by quality criteria, the ideation stage should be determined by quantity of ideas. Several papers have been published on the effect of software on creativity [40] [41] [42] [43] [44] [45]. Aiken et al. [46] [47] [48] and Aiken and Vanjani [49], for example, point out that electronic meeting techniques can improve group productivity in creative processes. Based on empirical evidence, Massetti [50] proves that ideas generated with software support are significantly more novel and valuable than results attained using traditional methods. Creativity software does not simulate creative processes; it stimulates them [51] by assisting in the recording, recalling and reconstructing of knowledge in creative processes [52] [53]. Beyond the stimulation of creativity, new information channels can be made available by lowering barriers for idea submission and simplifying the integration of external persons and institutions in the ideation process (e.g. experts, customers, suppliers, etc.).

\subsection{Limitations and Interdependencies between Categories of Potential Benefits}

The four categories of potential benefits of CAI software are summarized in Figure 2. The arrows between each of the four categories demonstrate that there are interdependencies between the benefits. 


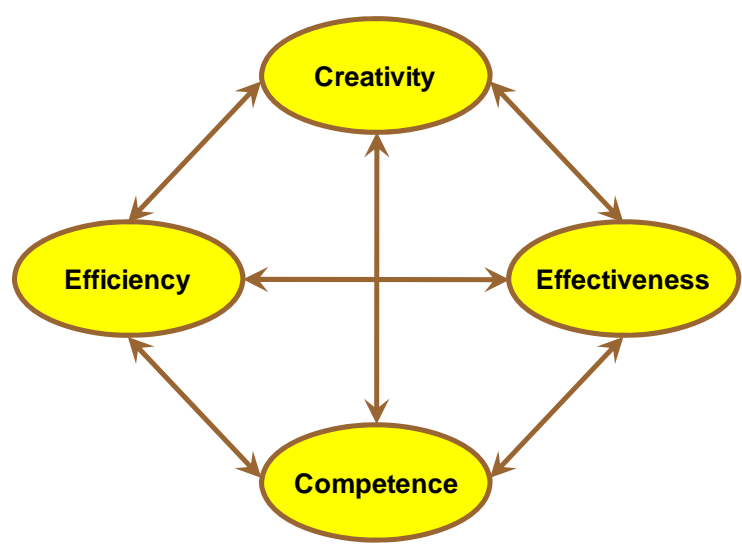

Figure 2: Advantages of CAI (Kohn and Hüsig, 2007).

The use of a better methodology to generate new ideas will facilitate the creativity of the user, leading to improved and more creative ideas. Collecting and aggregating huge amounts of data comfortably has been summarized in the efficiency-enhancing category. In many cases this data aggregation is the basis for improved decisions, leading to the improved effectiveness of the corporate innovation system based on its innovation software. However, it might be difficult to measure those benefits in an upfront costbenefit analysis or even ex post as in similar cases of IT systems, since their use is typically highly context-specific [17] [18] [36] [54].

\section{Major Trends in the CAI Supply}

There has been explosive growth in the development of ICT for NPD activities as technology has advanced and the importance of a formal NPD process has been recognized [9] [55] [19] [20] [22] [23] [56]. The most comprehensive surveys on the CAI supply available in the market were provided by Kohn and Hüsig [19] [20] and Spath et al. [56]. Therefore, most of the existing knowledge presented here is based on these empirical studies. Using the categorization scheme of Kohn and Hüsig [20] a descriptive statistical analysis of this market data reveals that the existing supply of CAI products is not distributed very homogenously over these categories. Table 1 in the appendix provides a comprehensive overview of the CAI-tools which were analysed.

As the further descriptive statistical analysis in Figure 3 shows, nearly the half of all CAI tools (46\%) fall into the "Idea Management" category. While 33\% of the CAI products studied by Kohn and Hüsig [20] support "Strategy Management", only 17\% are aimed at "Patent Management" activities. The category of "Holistic Solutions" is still underdeveloped with 4\% of the market supply. A look into the sub-categories of the CAI products indicates that within the individual categories the distribution is also quite uneven. There is a large difference in the market supply, for example, in the "Idea Management" category: Idea collection is supported by many products whereas idea classification is still a rather rare function of CAI tools. The same applies to scenario management in the "Strategy Management" category. This means that benefit gaps and offers in the actual supply still exist and some of the functional areas in the innovation process could be addressed with more or improved CAI products. This conclusion is also supported by Nyffenegger [22] in his small market survey based on an in-depth analysis of seven CAI products. At this point some opportunities for CAI vendors could be explored. Moreover, the market for CAI products appears to be in an interesting development phase. The large number of tools is also supplied by a huge number of suppliers, the majority of them small [19] [20]. With SAP AG, one of the largest software companies in the world, a major player has entered the market with a PLM-oriented approach [10]. This shows the potential of the market and might be the starting sign for a consolidation phase. From a user perspective it might be less suitable to have different products for different tasks in the innovation process. Therefore, more holistic solutions with different modules for certain innovation tasks are expected in the future [20]. On the other hand, two different strategies of the suppliers in the CAI market were identified: Modular versus integrated solutions [10] [20]. The modular strategy consists of CAI products which are focused on one special task of the innovation process, like patent search or idea generation. The second strategy consists of CAI tools that try to cover the whole innovation process and support each part of it with different modules. These CAI products strive for a higher integration degree with other innovation activities and systems. Further research could explore which strategy for CAI 
(modular vs. integration) might be the better development path. Maturity models like those developed by Bowden [10] would suggest that a stronger integration degree might be the avenue to future success. This aspect will be described in the next section.

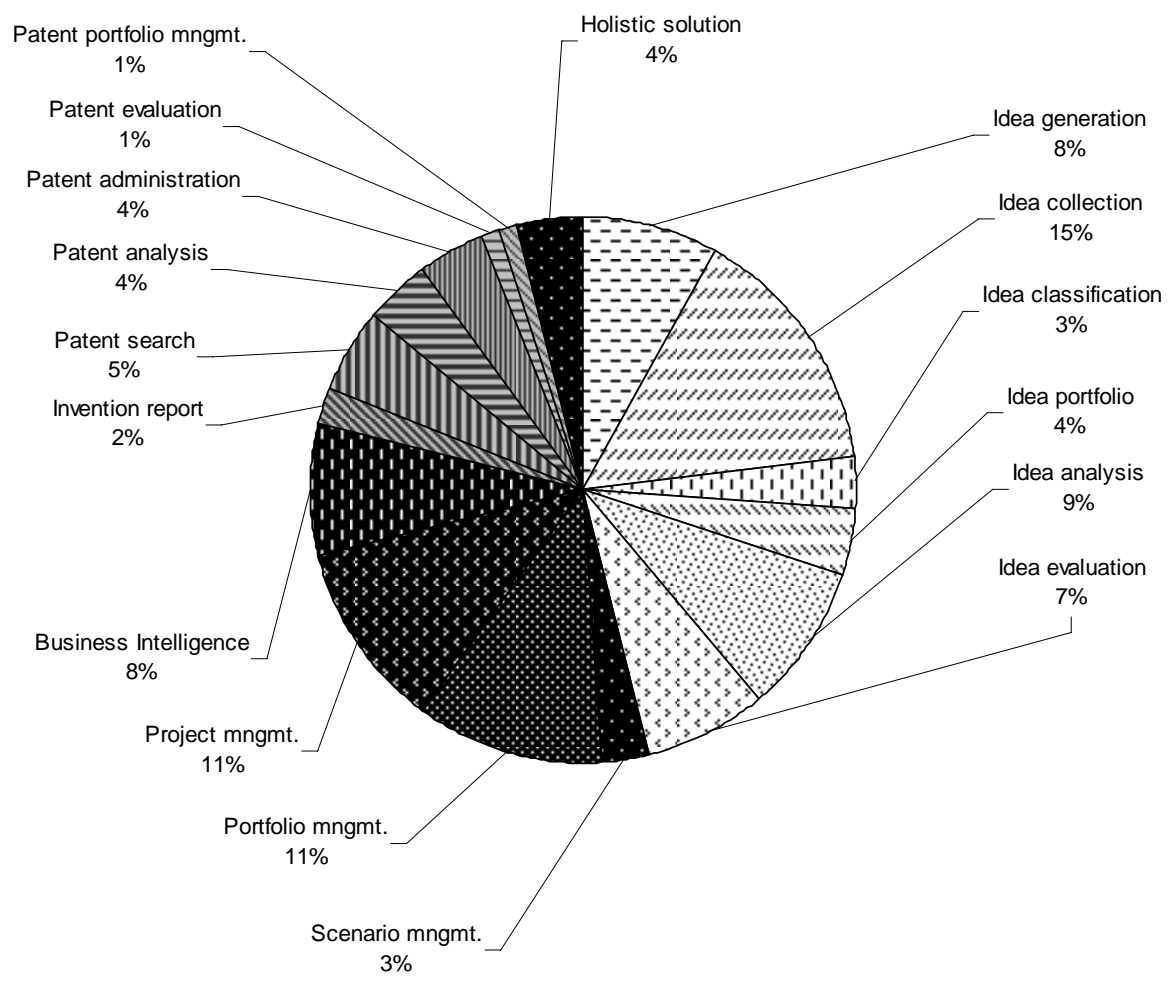

Figure 3: Percentages of CAI Tools in the Sub-Categories in the Sample of Kohn and Hüsig (2007).

\section{Maturity Models of CAI and NPD Systems}

Scholars in process management and information systems have developed a long tradition of analysing the development of IT usage or process capabilities by what are called maturity models [57] [58]. Maturity models typically consist of a structured collection of elements that describe certain aspects of maturity in an organization. A maturity model can be used as a benchmark for assessing different organizations for comparison and is frequently organized in hierarchical stages or levels. One wellestablished example is Humphrey's Capability Maturity Model (CMM) [57], which is a process capability maturity model to aid the definition and understanding of an organizational process. In the area of CAI and NPD systems, similar approaches are also starting to become popular, such as those by Bowden [10] and Cooper [59]. For the further development of the CAI field, these models could be important in two ways:

1. First, CAI maturity models could provide an orientation for future strategies of both CAI suppliers and developers, and guide buying or implementing decisions by users.

2. Second, these models are also interlinked with the process and management aspects of NPD, thus emphasizing a more holistic approach to CAI system development.

Since most CAI tools are targeted at an explicit NPD task or a process stage, it is essential to select carefully and match the right tool with the adequate method for the right task and phase of the NPD process as long the CAI tool is not a holistic solution. Moreover, even in this case, the maturity level of 
the NPD system must be analysed to provide a sufficient match between CAI and NPD. Unless CAI is embedded in people's work and processes, it will not be used and its benefits will not be realized [9] [19] [26]. To support this matching process, a maturity model for the NPD process developed by Cooper [59] might be helpful. In this model, Cooper [59] proposes different maturity stages which an organisation's NPD system must typically pass through. These stages are seen as a kind of natural evolutionary path down which an organisation has to proceed in its NPD capabilities. The stages are termed "generations", which start at the lowest level with an unmanaged NPD process followed by a first generation scheme called "phased review process". On this level, the NPD process is focused on technical milestones only and fails to integrate other functions or customer inputs.

Firms that use second-generation NPD processes like Stage-Gate systems can overcome some of these limitations and include cross-functional mechanisms and stronger market orientation. The highest level is reached when firms implement a third generation NPD process which is faster, parallel and more flexible than those from the second generation. It seems obvious that appropriate CAI systems should be adjusted to the maturity of the NPD system. Therefore, CAI systems might also need to be organized into a maturity model to match the two systems more simply. Bowden [10] develops such a maturity model for CAI with four stages which could be helpful for this process in a given firm environment. These stages partly reflect the CAI categorization of Kohn and Hüsig [20] as described above. Stage 0 means that an organisation has no IT-enabled NPD process. In Stage 1 people are using focused tools for specific NPD tasks. Organisations in Stage 2 have more holistic solutions that cover the whole process and related activities. The NPD process is widely captured in the IT system. Integration of an NPD process across different business units, and the inclusion of external partners like customers and suppliers in CAI systems characterizes companies that reach Stage 3. In these maturity models the stages are also seen as a kind of natural evolution path along which an organisation has to proceed. Therefore, this model suggests a staged introduction of CAI tools with respect to the actual stage. Figure 4 summarizes the stages of both models and the need to adjust the CAI systems according to those stages. Future research could empirically analyse the benefit of these models and develop them further.

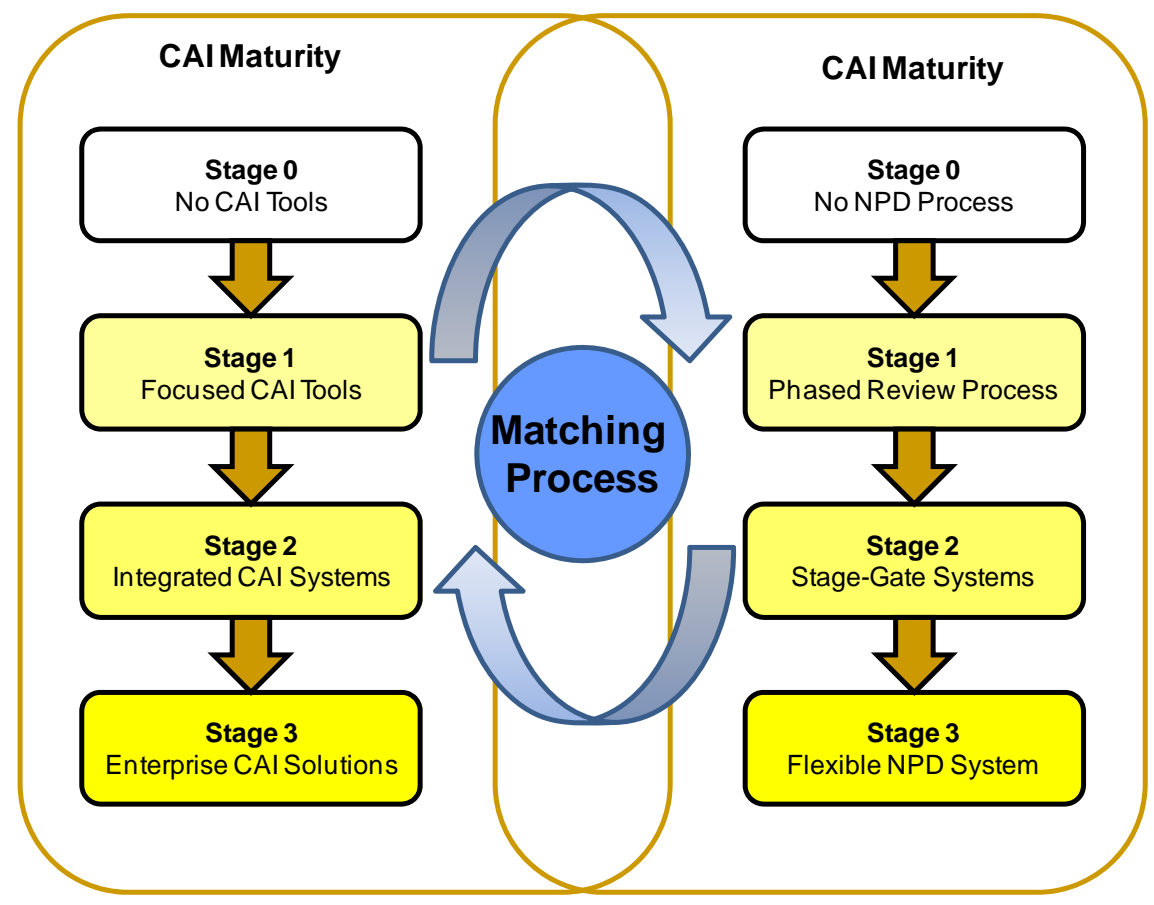

Figure 4: Need to match the CAI deployment with the maturity stages of CAI and NPD systems. 


\section{CAI Usage and Implementation Requirements}

\subsection{CAI Usage and Determinants of Adoption}

In spite of the efforts vendors have made to develop high-quality CAI tools, research suggests that companies are fairly immature in their use of IT for NPD [9] [29] [19] [30]. The recent Comparative Performance Assessment Study (CPAS) by the Product Development \& Management Association (PDMA), for example, found that less than $20 \%$ of the "best" firms used web-based market research tools and product portfolio management software, and less than $40 \%$ used groupware software to support their project teams [9]. Likewise, Barczak and Sultan [29] observe that NPD project teams tend to use simple, user-friendly, ubiquitous tools such as e-mail, Microsoft Office, and Excel/Access databases rather than more sophisticated and more complex CAI tools. Although more specific software support is available and useful, explorative research on the demand side of the uses of CAI software revealed that the benefits of specific innovation software are often not clear, or that there is a lack of knowledge about the existing solutions and off-the-shelf products on the market [19] [30].

Since many firms are not aware of the large supply of CAI products available, they use custom built solutions addressing this frequently underdeveloped area. Still, many of these self-developed tools lack integration in the surrounding infrastructure and often remain unexploited by the end user [26] [19] [30]. On the other hand, the suppliers of CAI software are also often unaware what kind of solutions there already are on the market or what benefit gaps in the actual supply have to be addressed to enhance the user experience [19] [20] [30]. Given that there is often uncertainty about the benefits and the types of CAI products in many firms, the adoption of CAI tools is still at an early stage and confronted with substantial resistance [9] [29] [19] [30] [26]. However, this might also be a question of firm size and industry. There is anecdotal evidence that TRIZ-based CAI tools are widespread and often used in the automotive industry [32]. Gartner Group also reports that $70 \%$ of the most innovative firms in the US Fortune 500 have already installed advanced CAI systems in the last few years. However, the use of CAI tools in SMEs might be significantly less widespread, as suggested by Kohn and Hüsig [19] [30] on the utilization and barriers to CAI adoption in German SMEs. They show that only $21 \%$ of the researched SMEs had considered using specific software solutions to support the innovation process. The rest of the firms had no experience with CAI at all. Therefore, the diffusion of CAI among German SMEs must be considered quite modest. This research indicates that even among the $21 \%$ of SMEs which considered using CAI, only approximately $50 \%$ had profound knowledge in this area. Only $6 \%$ of the SMEs in this sample were frequent users of CAI. However, further studies with larger samples need to be conducted to clarify the picture. In order to analyse the reasons for adoption or non-usage of CAI in more depth, some authors conduct empirical research into the determinants of adoption [9] [19] [30].

Kohn and Hüsig [19] try to identify reasons for the low acceptance of CAI among German SMEs. According to their findings, factors like technical infrastructure and lack of methodological know-how or importance of innovation activities cannot explain the low acceptance of CAI. However, they identify other barriers to the use of CAI. It seems that the low degree of diffusion in their sample of SMEs can be explained by two central factors: First, the rich supply of CAI products is unknown, and second, the benefits of CAI are not clear to the potential users. More than 50\% of the respondents had not heard of a single product out of the range of existing software solutions. The third most important barrier was the perceived cost of software products in general. Drawing on concepts and insights from the NPD, adoption and IT literature, Barczak et al. [9] identify six factors hypothesized to influence IT usage positively and relate them to CAI adoption in a broader sense:

- Project risk;

- Existence of a champion;

- Autonomy;

- Innovative climate;

- IT infrastructure; and

- IT embeddedness (which is the degree to which IT tools play a significant role in the development of new products).

The Barczak et al. study [9] sample was drawn from the mailing list of 1,371 PDMA (Product Development \& Management Association) practising members in the United States and Canada, with a $15.5 \%$ response rate. The companies participating in the study come from a variety of industries and are of different sizes. The result indicates that project risk, existence of a champion, and IT embeddedness have a significant, positive relationship with IT usage. Some organizational factors are highlighted by the 
finding regarding the existence of a champion, illustrating the importance of having enthusiastic and committed individuals who promote and support the usage of particular IT tools. The positive relationship between IT usage and the degree to which IT is embedded in the NPD process of the organization highlights the importance of IT integration. IT integration and embeddedness, in turn, are necessary if CAI is to be used to its maximum advantage [26]. Other relationships for CAI usage were not supported: autonomy, innovative climate, and IT infrastructure. The lack of any significant finding regarding IT infrastructure and CAI usage supports the findings of Kohn and Hüsig [19] [30]. Unfortunately, the study of Barczak et al. [9] lacks a clear definition of CAI and is mostly related to IT usage in NPD with generic tools, and therefore the result might not be important for the CAI field. This demonstrates the need for additional and more specific empirical research on this issue.

\subsection{Implementation Requirements of CAI}

Apart from larger empirical studies on CAI, there is also a rich area of research based on conceptual and case-study research, which aims to explain how CAI support is implemented successfully and which factors should be considered when CAI tools are selected or developed for a specific organizational context. Given that there is often uncertainty about the benefits and types of CAI tools in many firms, the adoption of CAI suffers and meets substantial resistance [9] [29] [19] [30]. This emphasizes Thomke's [26] and, similarly, Holstein's [18] contention that unless IT is embedded into people's work and processes, it will not be used and its benefits will not be realized. In this context it is important to emphasize the importance of the interrelation of process, methods and CAI [20] [7] [8]. The successful implementation and utilization of CAI products calls for a holistic view of all aspects of the NPD process, the specific tasks or methods, the types of information and knowledge to be processed and the people who are supposed to use them [19]. Without a sound combination and integration of all the components, none of the potential benefits - like enhanced learning or efficiency gains - will materialize. CAI cannot be isolated to its technological dimension only. Without a structured and goal-oriented innovation process, any software support will downgrade the inherent weaknesses of an inadequate NPD structure [7]. These aspects need to be emphasized before expectations of potential benefits are exaggerated and misunderstood by solution-seeking NPD managers who try to fix organisational problems with technological solutions. A misuse of CAI will ultimately lead to disappointment and would harm the potential of future developments in this promising field.

Although maturity models provide an initial insight into the interrelations of organizational factors like the maturity of the NPD process and the technological environment such as CAI, more elaborate implementation frameworks incorporate more factors in the context of CAI selection, usage and implementation [9] [16] [17] [18] [36] [54] [7]. One of the most elaborate frameworks for CAI was proposed by Kohn and Hüsig [19], who developed a combination of factors for the successful selection and implementation of CAI based on information systems theories and case studies. This framework emphasizes the interrelations between the fit of a specific CAI solution for a certain context and the most important context factors, which are identified as dimensions of technology, people, organization and task. This framework is displayed in Figure 5. The single dimensions of these context factors are detailed in the framework. An overview is given here for the single dimensions. According to Kohn and Hüsig [19] the fit of CAI depends on:

- People who are (not) going to use the tools because of their knowledge, motivation and capacity.

- The organization which supports the development, purchase or implementation of CAI through top management support, sufficient resources, incentives for usage, empowerment of users, supportive culture, maturity and style of innovation process and a supportive technology/implementation strategy for internal IT. Finally the organisational requirements and the total costs of usage should be balanced.

- Tasks which match their innovation methods, type of information and project, scope of support needs and integration of external or distant parties with the selected CAI support.

- The technology of the CAI which fits with the compatibility with systems and infrastructure of the context environment, integration of data and methods, stability of supply/vendor, or implementation of further development. Additionally, the fit of the CAI-tool's technology aspects like ergonomic design and flexibility must fit with the user requirements to be accepted and used successfully. The CAI system should also fit with future trends in technology. 
In an ideal case all of these implementation requirements have a perfect fit with a specific CAI system for a given context. Future research should further elaborate such frameworks theoretically, and test their validity empirically.

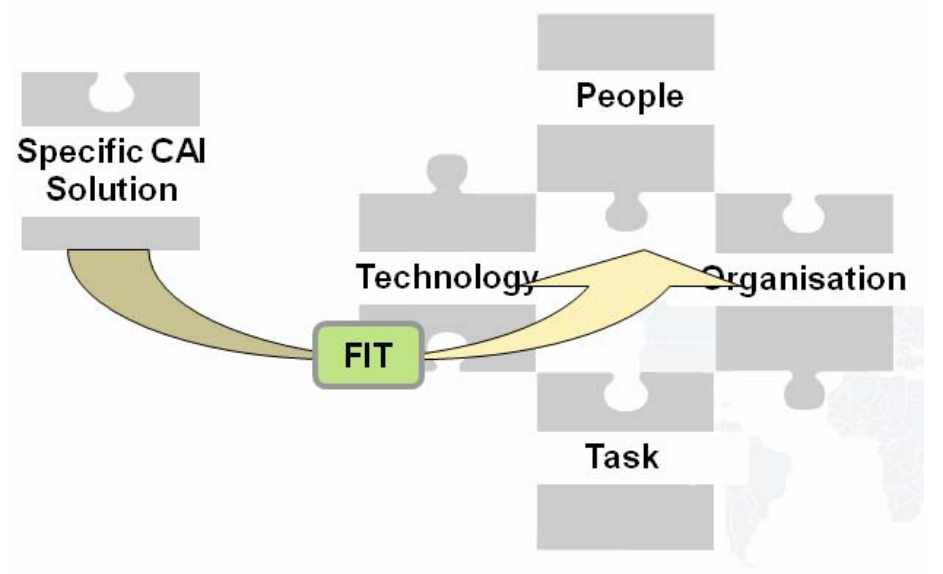

Figure 5: Selection and implementation framework for CAI by Kohn and Hüsig (2003).

\section{Conclusions and Further Research Directions}

Summing up the state of the art in the field of CAI from an NPD perspective, it can be concluded that many of the presented research areas lack integration and still need to be developed further in various directions. First, based on a holistic understanding of the innovation process and its support by ICT, CAI needs to be understood more holistically than it has been in the past, especially from an engineering perspective, which used to be focused on the inventive stage [31]. The research on the concept of CAI and its categorization indicates the possible amplitude of CAI. However, the competition between concepts and approaches is ongoing. It can be observed, for example, that PLM and ERP systems are moving into the CAI field. Scholars should therefore research interfaces between the different tools and advise the software industry on how to incorporate different methodologies in order to develop the optimal integrated CAI solution. On the other hand, CAI needs to be distinguished from generic ICT support in the NPD to gain better and more specific insights into CAI usage and effectiveness. Therefore, the categorization scheme by Kohn and Hüsig [20] might help to improve the transparency of the CAI supply and support the clarification of the CAI term, whose definition is still fuzzy. However, this must be seen as a starting point for a discussion about a precise CAI definition and classification. The categorization might be extended or altered in order to develop a common understanding. This approach needs to be developed further since the CAI field is in a constant state of flux and this framework is no more than a snapshot of the current situation. Additionally, other areas of CAI might be underrepresented in this categorization scheme, such as other CAx technologies or PLM tools which might migrate more into the CAI field. At this point a need for even more integrated and holistic understanding of the CAI term might provide further sub-categories or enhance the comprehensiveness of future frameworks and CAI definitions. Further research should also develop sound criteria for the evaluation of CAI tools.

Since there is uncertainty about the benefits and types of CAI products in the market and a lack of academic research in this area, it is also important to provide a better understanding of the benefits and categories of CAI in the communication with potential users. Here, we presented a more systematic categorization of the potential benefits of CAI which summarizes the state of the art in this area. The potential benefits of CAI products can be categorized as efficiency, effectiveness, competence and creativity enhancing [19] [20]. These potential benefits attracted various CAI vendors, as a look at the current trends of the CAI supply shows. There has been explosive growth in the development of ICT for NPD activities [9] [55] [19] [20] [22] [23] [56]. The most comprehensive surveys on the CAI supply available in the market were provided by Kohn and Hüsig [19] [20] and Spath et al. [56]. Therefore, most of the existing knowledge reported in this paper is based on these empirical studies. More knowledge in this area would be useful, especially regarding CAI tools developed in-house. Not much information on this aspect is available so far. Moreover, further research could explore which strategy might point to the better development path for the future development of CAI - modular or integrated. Maturity models like 
Bowden [10] developed would suggest that a stronger degree of integration might be the avenue to future success. Future research could analyse the benefit of these models empirically and develop them further.

A closer look at CAI usage shows that in spite of the efforts vendors have made to develop high-quality CAI tools, research suggests that companies are fairly immature in their use of IT for NPD [9] [29] [19] [30]. Even if not much empirical evidence on this issue is available specifically for CAI, this might provide an initial view of the CAI adoption situation. Further studies with larger samples need to be conducted to clarify the picture. In the case of SMEs it seems that the low degree of diffusion can be explained by the unfamiliarity of the innovation professionals in these firms with the rich supply of CAI products and that the benefits of CAI are not clear to the potential users [19] [30]. Barczak et al. [9] demonstrate that project risk, existence of a champion, and IT embeddedness have a significant, positive relationship with CAI usage. Unfortunately, not all studies use a clear definition of CAI and are mostly related to IT usage in NPD with generic tools, and therefore the results might not be important for the CAI field. This underlines the need for more specific empirical research on this issue. The same is true for implementation frameworks. These frameworks emphasize the interrelations between the fit of specific CAI solutions for a certain context and the most important context factors, which are identified as technology, people, organization and task [19]. Although initial insights were provided via conceptual and case-study research, future research should further elaborate such frameworks theoretically and empirically test their validity.

Recently, increasing attention has also been paid to the integration of customers in the front end of the NPD process and co-operative innovation processes by specific ICT support [39]. These developments fit in the broader context of the Open Innovation paradigm identified by Chesbrough [60], which highlights the role of external entities in the innovation process. In this context innovation-specific tools are developed for certain tasks which customers will fulfil during the front end of the NPD process and enhance the knowledge base through early interaction with customers. These new developments could be further integrated in the traditional CAI field, which focuses primarily on the closed innovation paradigm. Finally, with the growing attention in the NPD area, the connection and use of CAI for radical innovation processes also need to be explored [30].

Overall, the emerging field of CAI has recently been the focus of more attention in the NPD area, as the publications of Barczak et al. [9], Durmusoglu et al. [14], Thomke [26] or Cascini and Russo [33] indicate. Nevertheless, this research needs to be further integrated with the insights from the other research traditions outlined in this paper here to gain a more holistic perspective of CAI.

\section{References}

[1] R. Garcia, R. Calantone, A critical look at technological innovation typology and innovativeness terminology: A literature review, Journal of Product Innovation Management 19 (2002) pp. 11032.

[2] J. Hauschildt, Innovationsmanagement, Vahlens Handbücher, Munich, 2004.

[3] S. Hüsig, Institutionalisierte Vorentwicklung für radikale Innovationen - Dargestellt am Beispiel der Mannesmann Pilotentwicklung und der LKW-Mauttechnik, WiKu-Verlag, Duisburg, Germany, 2006.

[4] R. Cooper, Winning at New Products - Accelerating the Process from Idea to Launch. 3rd ed. Perseus Books Group, Jackson TN, 2001.

[5] H. Geschka, Wettbewerbsfaktor Zeit - Beschleunigung von Innovationsprozessen, GRIN, Landsberg am Lech, Germany, 1993.

[6] A. Griffin, PDMA research on new product development practices: Updating trends, and benchmarking best practices, Journal of Product Innovation Management 14 (1997) pp. 429-58.

[7] SC. Wheelwright, KB. Clark, Revolution der Produktentwicklung Spitzenleistungen in Schnelligkeit, Effizienz und Qualität durch dynamische Teams, Campus Verlag, Frankfurt a.M., New York, 1994.

[8] G. Specht, C. Beckmann, F\&E - Management, Schäffer-Poeschel Verlag, Stuttgart, Germany, 1996.

[9] G. Barczak, F. Sultan, EJ. Hultink, Determinants of IT usage and new product performance. Journal of Product Innovation Management, 24 (2007) pp. 600-13.

[10] M. Bowden, The role of IT in new product development today. Visions 1 (2004) pp. 1-8.

[11] HD. Bürgel, C. Haller, M. Binder, F\&E - Management, Verlag Vahlen, Munich, 1996. 
[12] M. Caputo, P. Salvatore, F.Zirpoli, Opportunities and threats of computer based product development. In: Proceedings of the 10th Int. NPD Management Conference, Brussels, (2003) pp. 1187-201.

[13] JM. Choffray, GL. Lilien, A decision-support system for evaluating sales prospects and launch strategies for new products, Industrial Marketing Management 15 (1986) pp. 75-85.

[14] S. Durmusoglu, R. Calantone, V. Sambamurthy, Is more information technology better for new product development? Journal of Product \& Brand Management, 15 (7) (2006) pp. 435-41.

[15] J. Elam, M. Mead, Can software influence creativity? Information Systems Research, 1 (1) (1990) pp. 1-22.

[16] W. Esswein, G. Heinatz, Informationssysteme im Innovationsmanagement. In: C. Tintelnot, D. Meißner, I. Steinmeier, editors, Innovationsmanagement, Berlin, Heidelberg, 1999, pp. 91-8.

[17] I. Hofacker, Systemunterstützung strategischer Entscheidungsprozesse. Wiesbaden, Germany, 1999.

[18] WK. Holstein, Decision support systems for strategic management: what will DSS systems do to help senior managers with strategic management tasks? In: R. Berndt, editor. Unternehmen im Wandel - Change Management, Zürich, 1998, pp. 379-92.

[19] S. Kohn, S. Hüsig, Software im Innovationsprozess. Insti Studienreihe, 2003.

[20] S. Kohn, S. Hüsig, Development of an empirical based categorisation scheme for CAI software. International Journal of Computer Applications in Technology, 30 (1/2) (2007) pp. 33-46.

[21] N. León-Rovira, J. Ovtcharova, Trends in computer aided innovation. $1^{\text {st }}$ IFIP working conference on computer aided innovation, Nov. 14-15, 2005, Ulm, Germany.

[22] F. Nyffenegger, Informationstechnische Unterstützung der frühen Phasen der Produktinnovation. Technische Wissenschaften, Eidgenössische Technische Hochschule ETH Zürich, Nr. 16993; 2006.

[23] M. Ozer, Information technology and new product development, Industrial Marketing Management, 29 (2000) pp. 387-96.

[24] A. Rangaswamy, GL. Lilien, Software tools for new product development, Journal of Marketing Research 34 (1997) pp. 177-84.

[25] R. Sethi, S. Pant, A. Sethi, Web-based product development systems integration and new product outcomes: a conceptual framework. Journal of Product Innovation Management, 20 (2003) pp. 37 56.

[26] S. Thomke, Capturing the real value of innovation tools, Sloan Management Review, 47 (2006) (2) pp. 24-32.

[27] DL. Young, Decision support and idea processing systems, Dubuque, IA, 1989.

[28] J. Fischer, F\&E - Informationssysteme: Hilfsmittel oder Treiber im Innovationsprozess? Arbeitskreis Forschungs- und Entwicklungsmanagement der Schmalenbach-Gesellschaft für Betriebswirtschaft e.V., Köln, Paderborn, 2003.

[29] G. Barczak, F. Sultan, Use IT or lose it, Marketing Management 15 (2) (2006) pp. 30-4.

[30] S. Kohn, S. Hüsig, Potential benefits, current supply, utilization and barriers to adoption: an exploratory study on German SMEs and innovation software, Technovation, 26 (8) (2006) pp. 988-98.

[31] N. León-Rovira, J. Ovtcharova, Editorial special issue on computer-aided innovation, International Journal of Computer Applications in Technology, 30 (1/2) (2007) pp. 1-2.

[32] E. Schüler-Hainsch, A. Ulbrich, A. Jost, TRIZ und CAI in der Automobilindustrie. In: C. Gundlach, H. Nähler, editors. Innovation mit TRIZ- Konzepte, Werkzeuge, Praxisanwendungen, Düsseldorf: Symposion, 2006, pp. 513-32.

[33] G. Cascini, D. Russo, Computer-aided analysis of patents and search for TRIZ contradictions, International Journal of Product Development ,4 (1-2) (2007) pp. 52-67.

[34] G. Altshuller, The innovation algorithm. TRIZ, systematic innovation and technical creativity, Technical Innovation Center Inc, Worcester MA, 1999.

[35] RR. Reeder, EG. Brierty, BH. Reeder, Industrial Marketing Analysis, Planning and Control, Englewood Cliffs NJ, 1991.

[36] O. Kessing, H. Fischer, DO. Neeb, Implementation einer computergestützten strategischen Geschäftsfeld-Analyse, Zeitschrift für Planung, (1994) pp. 315-33.

[37] K. Helbig, V. Lingnau, Innovationscontrolling - Die Anwendung standardisierter Verfahren im Rahmen der Produktplanung von Investitionsgütern in der deutschen Industrie, Zeitschrift für Planung, 10 (1) (1999) pp. 67-84.

[38] MK. Welge, A. Al-Laham, Stand der strategischen Planungspraxis in der deutschen Industrie, Zeitschrift für betriebswirtschaftliche Forschung ,49 (9) (1997) pp. 790-806. 
[39] C. Wecht, P. Baloh, Open innovation: can modern ICT-tools facilitate customer integration into the fuzzy front end of the innovation process? In: D. Bennett et al., editors. Technology and global integration. Proceedings of the Second European Conference on Management of Technology, September 10-12, 2006, Birmingham, Aston Business School, Coral Gables: International Association for Management of Technology, pp. 713-20.

[40] GM. Marakas, J J. Elam, Creativity enhancement in problem solving: through software or process? Management Science, 43 (8) (1997) pp. 1136-46.

[41] T. Proctor, Experiments with two computer assisted creative problem-solving aids, International Journal of Management Science, 17 (2) (1989) pp. 197-200.

[42] M. Roberts, Brainstorming by computer, Psychology Today ,July/August:51, 1989.

[43] NE. Rouse, Brainstorming software unlocks creativity, Machine Design, October 12 (1989) pp. $100-2$.

[44] RJ. Thierauf, Creative computer software for strategic thinking and decision making, Quorum Books, Westport CT, 1993.

[45] DL. Watson, Enhancing creative productivity with the Fisher Association lists, Journal of Creative Behavior 23 (1) (1989) pp. 51-8.

[46] M. Aiken, J. Krosp, A. Shirani, J. Martin, Electronic brainstorming in small and large groups. Information and Management, 27 (1994) pp. 141-9.

[47] M. Aiken, M. Vanjani, J. Paolillo, A comparison of two electronic idea generation techniques. Information and Management, 30 (1996) pp. 91-9.

[48] M. Aiken, H .Sloan, J. Paolillo, L. Motiwall, The use of electronic idea generation techniques in strategy planning meetings, Journal of Business Communication, 34 (4) (1997) pp. 370-82.

[49] M. Aiken, M. Vanjani, Idea generation with electronic pool writing and gallery writing, International Journal of Information and Management Sciences, 7 (1996) pp. 1-9.

[50] B. Massetti An empirical examination of the value of creativity support systems on idea generation, MIS Quarterly, 20 (1) (1996) pp. 83-97.

[51] K. Heger, Jumpstarting the brain - whiz...bang...eureka - the automation of creativity, IABC Communication World, Nov. (1991) pp. 18-21.

[52] G. Haman, Techniques and tools to generate breakthrough new product ideas. In: MD. Rosenau Jr, A. Griffin, GA. Castellion, NF. Anschuetz, editors, The PDMA Handbook of New Product Development, New York, 1996, pp. 167-77.

[53] G. Erman, Roles for software. In: MD. Rosenau Jr, A. Griffin, GA. Castellion, NF. Anschuetz, editors, The PDMA Handbook of New Product Development, New York, 1996, pp. 512-17.

[54] D. Lütolf, Entwicklung und Einführung entscheidungsunterstützender Computermodelle für das Strategische Management. Peter Lang Bern, Frankfurt am Main, New York, 1989.

[55] CM. Chang, Web-based tools for product development, International Journal of Product Development, 3 (2) (2006) pp. 167-80.

[56] D. Spath, K. Auernhammer, A. Ardilio, S. Kohn, editors, Marktstudie Innovationssysteme: ITUnterstützung im Innovationsmanagement, Fraunhofer Institut für Arbeitswissenschaft und Organisation IAO. Fraunhofer IRB Verlag, Stuttgart, 2004.

[57] WS. Humphrey, Managing the software process, Addison Wesley Professional, Reading MA, 1989.

[58] RL. Nolan, Managing the computer resource: a stage hypothesis, Communications of the ACM, 16 (7) (1973) pp. 399-405.

[59] RG. Cooper, Perspective third-generation new product processes, Journal of Product Innovation Management, 11 (1) (1994) pp. 3-14.

[60] HW. Chesbrough, Open innovation. The new imperative for creating and profiting from technology, Harvard Business School Press, Boston MA, 2003. 


\section{Biographies of the Author}

\begin{tabular}{|l|l|}
\hline & $\begin{array}{l}\text { Stefan Hüsig has a PhD in Business Administration and holds } \\
\text { the position of Assistant Professor at the Chair of Innovation } \\
\text { and Technology Management at the University of Regensburg, } \\
\text { Germany. In addition, he works as a consultant in the area of } \\
\text { Innovation Management, where he has worked with Vodafone } \\
\text { R\&D, deep innovation, Mannesman Pilotentwicklung, } \\
\text { Fraunhofer Technology Development Group and other firms. } \\
\text { His research interests are the areas of predevelopment, } \\
\text { radical/disruptive innovations, corporate entrepreneurship and } \\
\text { Computer-Aided Innovation (CAI). }\end{array}$ \\
\hline & $\begin{array}{l}\text { Stefan Kohn is head of innovation management at FUJIFILM } \\
\text { Europe GmbH. Before that he was head of the department for } \\
\text { "Innovation and IP Management" for the Fraunhofer } \\
\text { Technology Development Group. He is a board member of } \\
\text { PDMA e.V., certified New Product Development Professional, } \\
\text { and has several years' experience in the field of innovation } \\
\text { management. He has a degree in Mechanical Engineering and } \\
\text { Business Administration from the Darmstadt University of } \\
\text { Technology. Besides his work he is a part-time PhD student at } \\
\text { the Otto Beisheim Graduate School of Management in } \\
\text { Vallendar. His research focuses on the front end of innovation. }\end{array}$ \\
\hline
\end{tabular}


Appendix: Table 1: List of examined software products (Kohn and Hüsig, 2007).

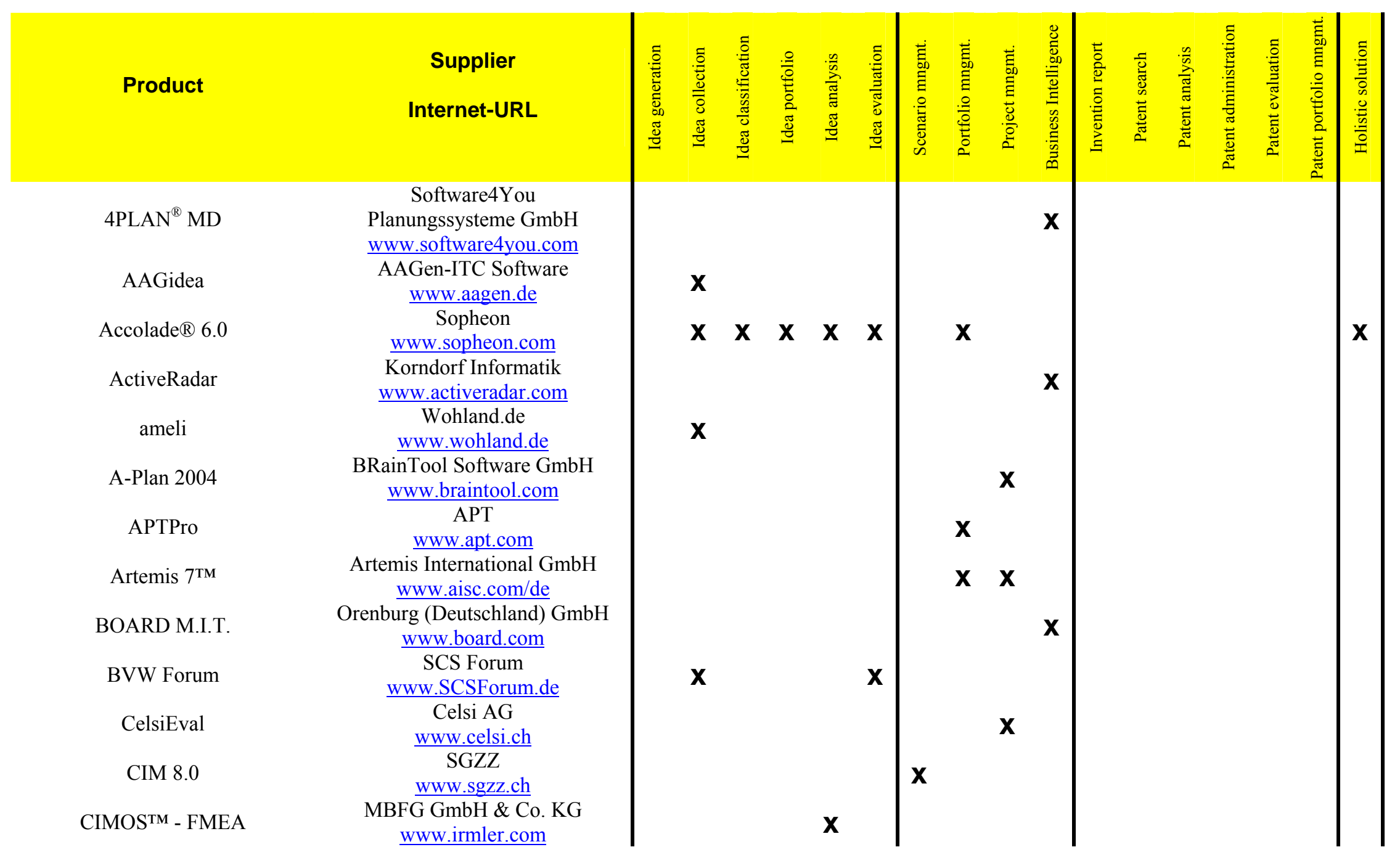




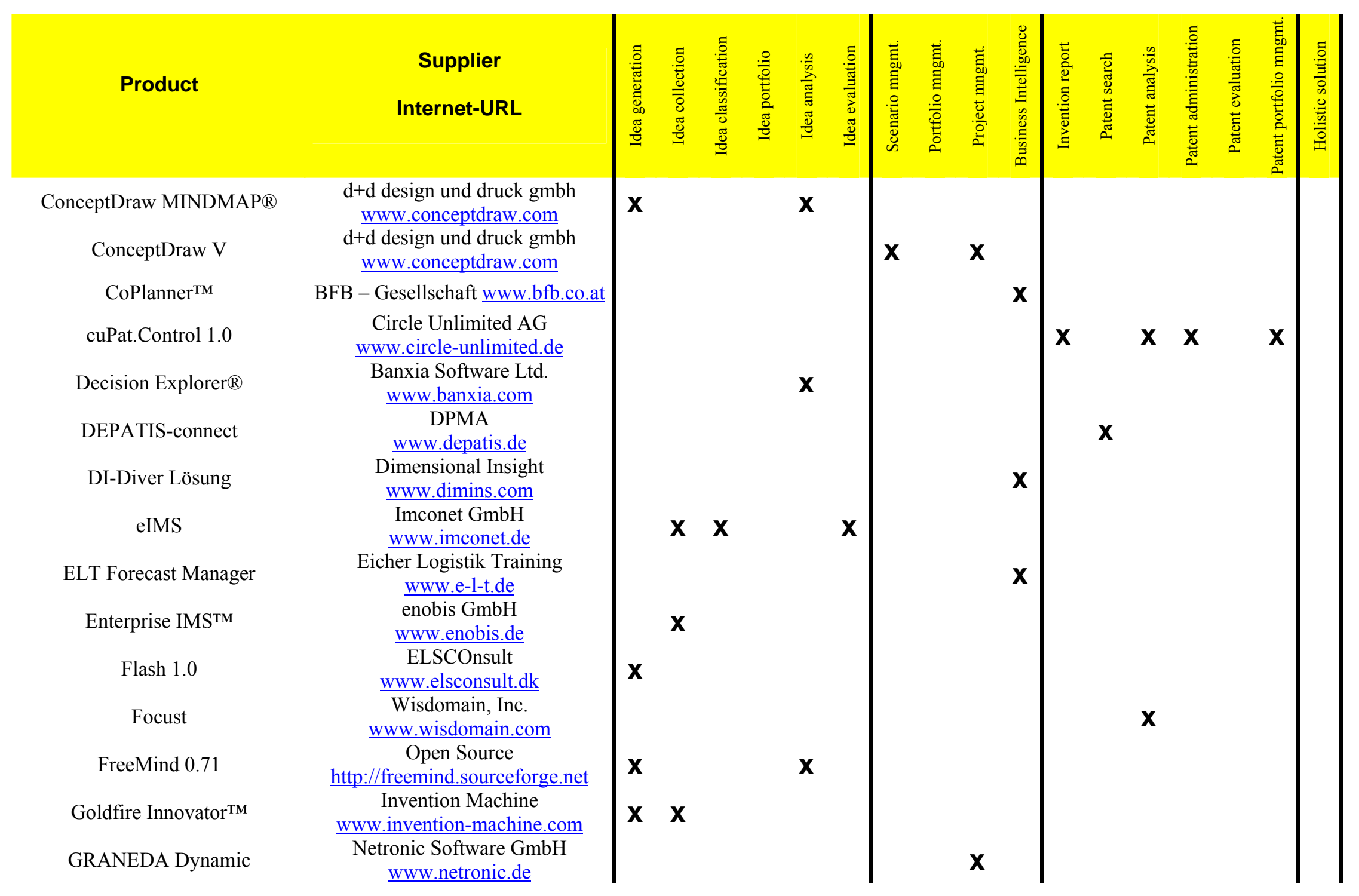




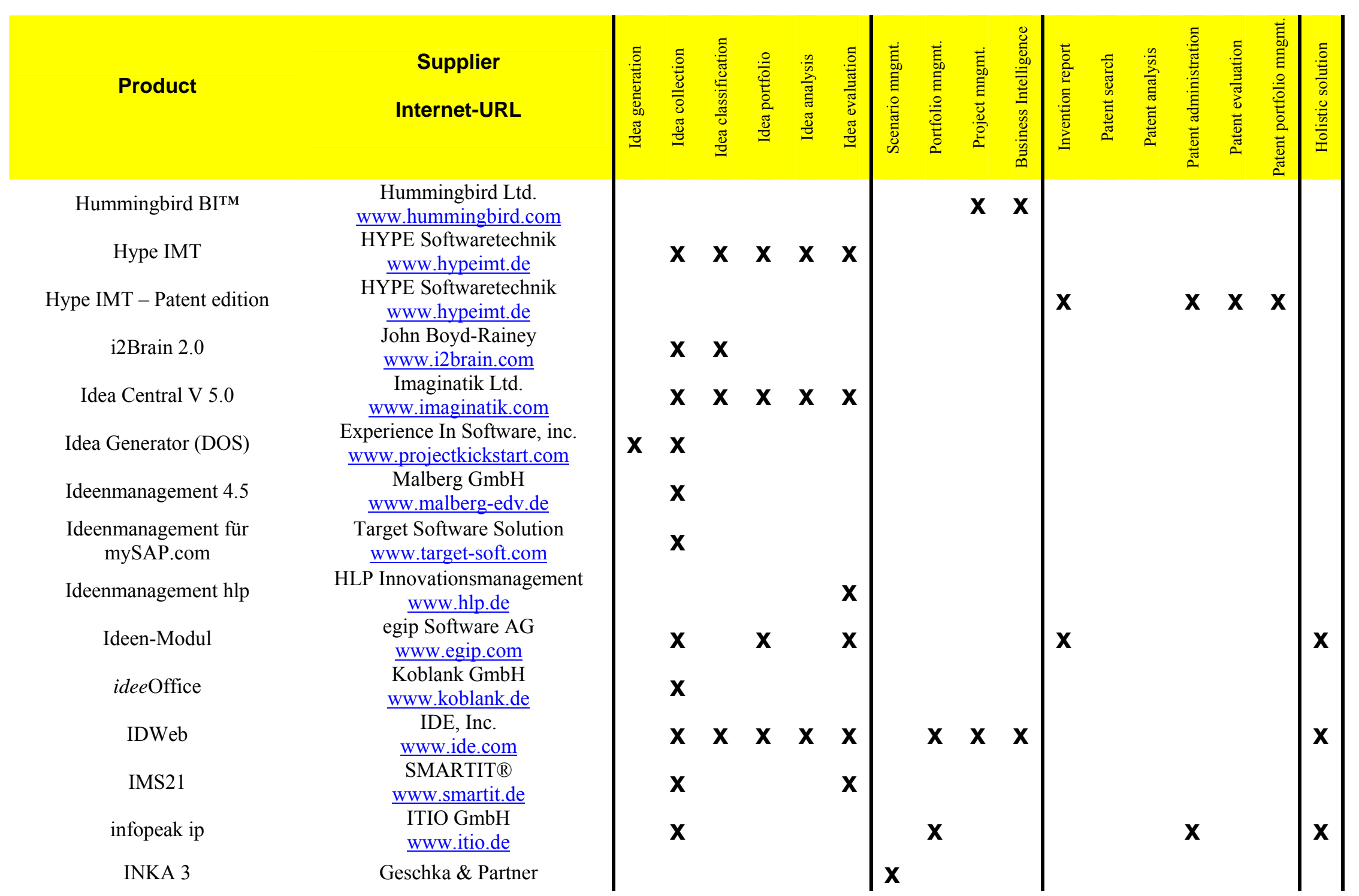




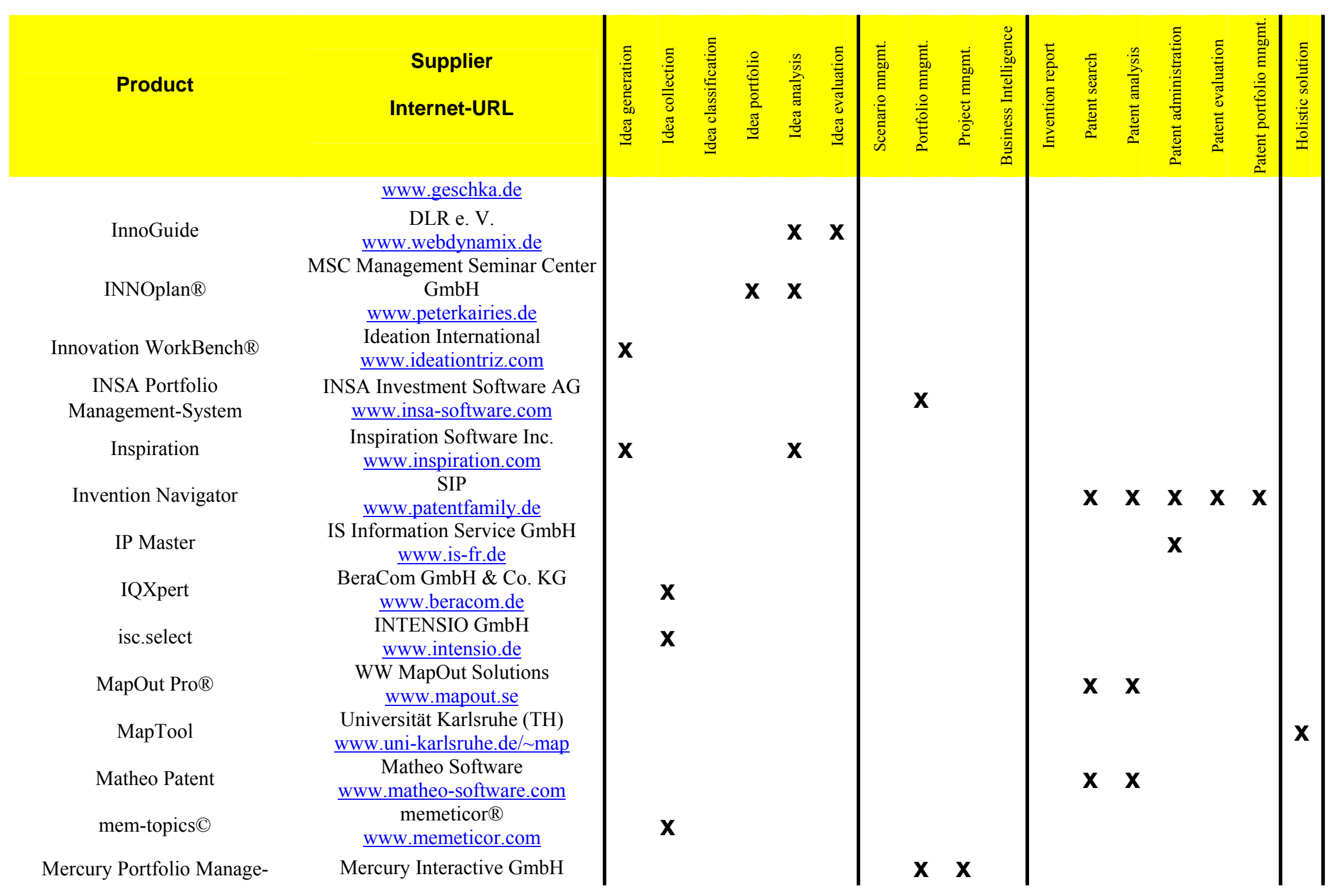




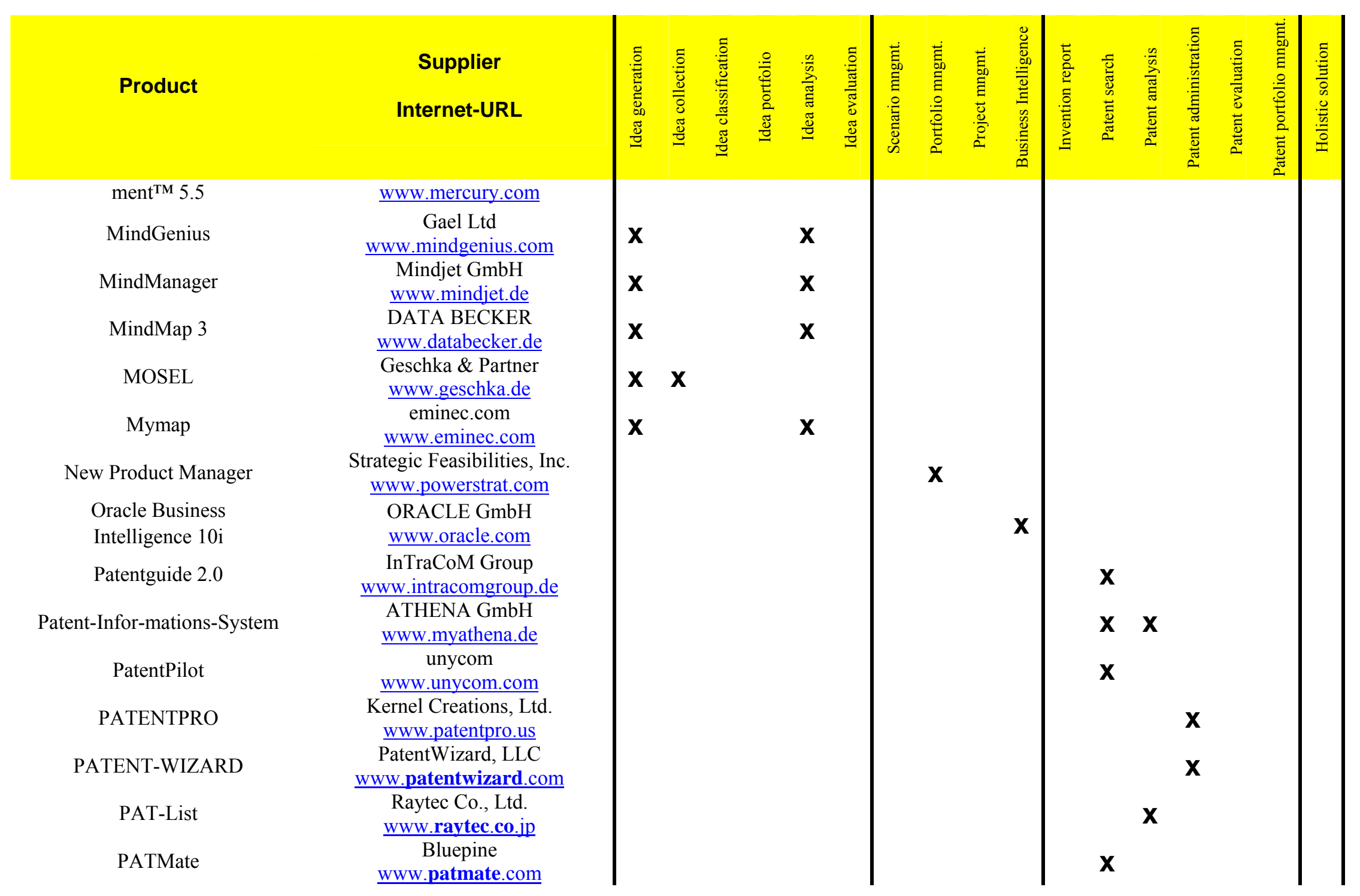




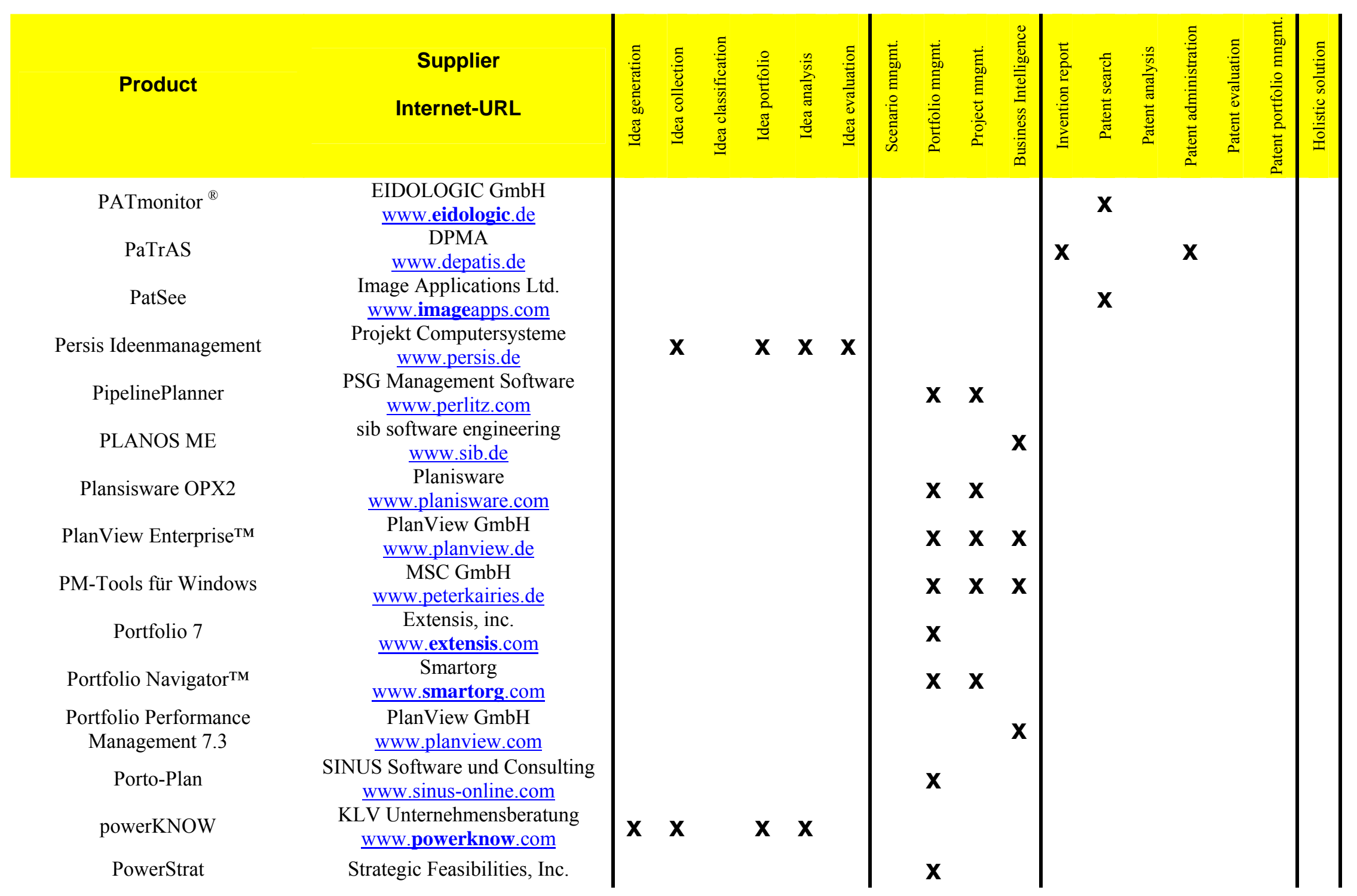




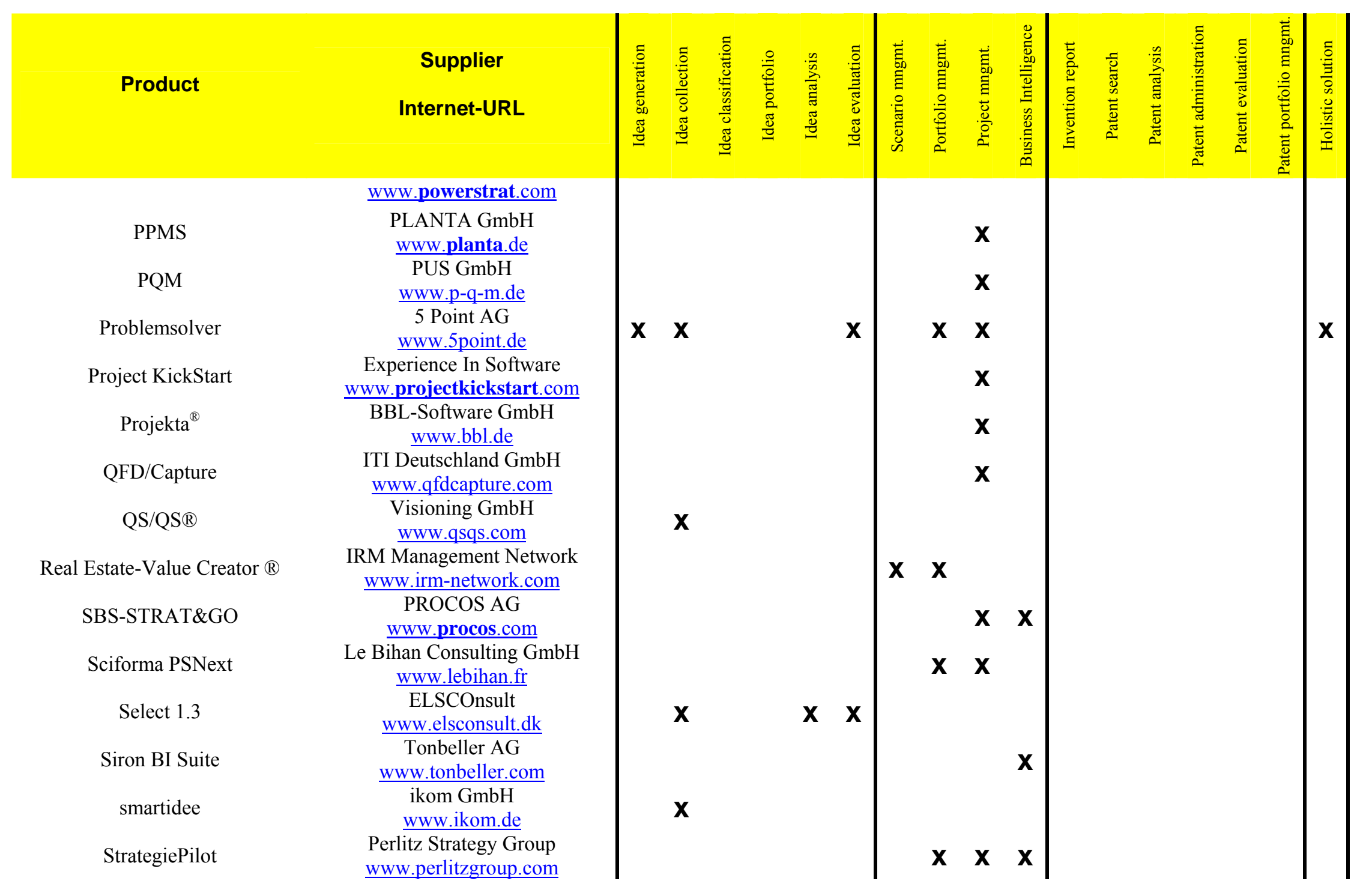




\begin{tabular}{|c|c|c|c|c|c|c|c|c|c|c|c|c|c|c|c|c|c|c|}
\hline Product & $\begin{array}{c}\text { Supplier } \\
\text { Internet-URL }\end{array}$ & 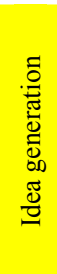 & $\begin{array}{l}\tilde{0} \\
\stackrel{0}{0} \\
\stackrel{0}{0} \\
0 \\
\mathbb{J} \\
\mathbb{\Xi}\end{array}$ & 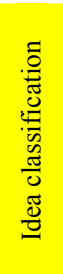 & 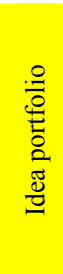 & 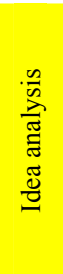 & 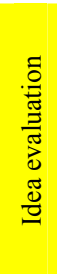 & 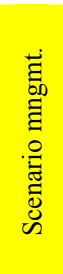 & 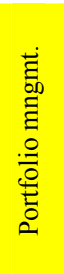 & 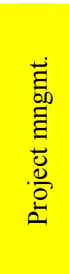 & 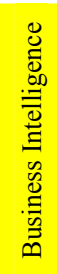 & 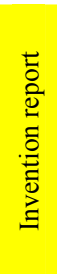 & 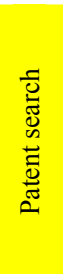 & 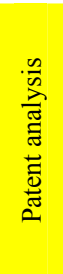 & 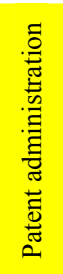 & 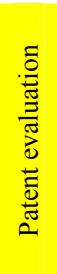 & 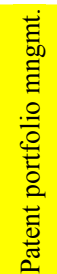 & 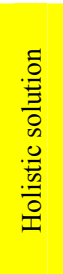 \\
\hline $\begin{array}{c}\text { StrategiePlanner } \\
\text { Strategie Portfolio } 3.5\end{array}$ & $\begin{array}{c}\text { Perlitz Strategy Group } \\
\text { www.perlitzgroup.com } \\
\text { Dr. Andreas Lindae-Software } \\
\text { www.lindae-software.com }\end{array}$ & & & & & & & $\mathbf{x}$ & $\mathbf{x}$ & & & & & & & & & \\
\hline Success-Manager & $\begin{array}{c}\text { Ratio Betriebsberatung } \mathrm{Gmb} H \\
\text { www.ratio.at }\end{array}$ & $\mathbf{x}$ & & & & $\mathbf{X}$ & $\mathbf{x}$ & & $\mathbf{x}$ & & $\mathbf{x}$ & & & & & & & $\mathbf{X}$ \\
\hline $\begin{array}{l}\text { Szeno-Plan } \\
\text { teamspace }\end{array}$ & $\begin{array}{l}\text { SINUS Software und Consulting } \\
\frac{\text { www.sinus-online.com }}{5 \text { Point AG }} \\
\text { www.5point.de }\end{array}$ & & & & & & & $\mathbf{X}$ & & $\mathbf{x}$ & & & & & & & & \\
\hline ThoughtPath & $\begin{array}{c}\text { Inventive Logic, Inc. } \\
\text { www.inventivelogic.com }\end{array}$ & $\mathbf{X}$ & & & & & & & & & & & & & & & & \\
\hline TopInfo-R & $\begin{array}{c}\text { F\&F Computeranwendungen } \\
\text { und Unternehmensberatung } \\
\text { www.ff-muenchen.de }\end{array}$ & $\mathbf{x}$ & $\mathbf{X}$ & & & & $\mathbf{x}$ & & & $\mathbf{x}$ & & & & & & & & $\mathbf{X}$ \\
\hline TriSolver4.net & $\begin{array}{c}\text { TriSolver GmbH \& Co. KG } \\
\text { www.trisolver.de }\end{array}$ & $\mathbf{X}$ & $\mathbf{X}$ & & $X$ & $X$ & & & & & & & & & & & & \\
\hline Visual-XSel 9.0 & CRGRAPH & & & & & & & & & & & & & & & & & \\
\hline DoE \& Weibull & www.crgraph.de & & & & & & & $\mathbf{X}$ & & & & & & & & & & \\
\hline $\mathrm{VKC}$ & $\begin{array}{c}\text { Siemens SBS / C-LAB } \\
\text { www.c-lab.de }\end{array}$ & & & & & & & & & & & & & & $\mathbf{X}$ & & & \\
\hline WebFocus & $\begin{array}{c}\text { Information Builders } \mathrm{GmbH} \\
\text { www.informationbuilders.com }\end{array}$ & & & & & & & & & & $\mathbf{x}$ & & & & & & & \\
\hline WebSCW & $\begin{array}{c}\text { confuture GmbH } \\
\text { www.confuture.com }\end{array}$ & & $\mathbf{X}$ & & & & $\mathbf{x}$ & & & & & & & & & & & \\
\hline WriteEZ & $\begin{array}{l}\text { Experience In Software, inc. } \\
\text { www.projectkickstart.com }\end{array}$ & $\mathbf{X}$ & $X$ & & & & & & & & & & & & & & & \\
\hline X/PAT 3000 & $\begin{array}{l}\text { G.E.I. KRAMER \& HOFMANN } \\
\text { www.interhost.de }\end{array}$ & & & & & & & & & & & & $\mathbf{X}$ & $\mathbf{X}$ & & & & \\
\hline
\end{tabular}




\begin{tabular}{|c|c|c|c|c|c|c|c|c|c|c|c|c|c|c|c|c|c|c|}
\hline Product & $\begin{array}{c}\text { Supplier } \\
\text { Internet-URL }\end{array}$ & 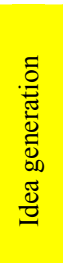 & 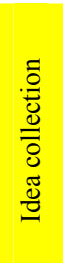 & 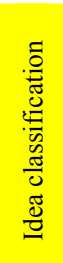 & 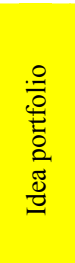 & 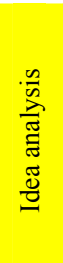 & 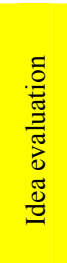 & 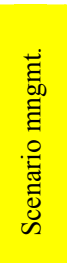 & 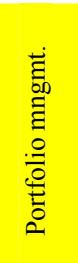 & 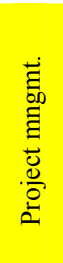 & 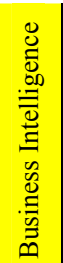 & 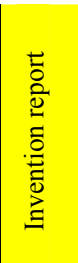 & 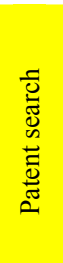 & 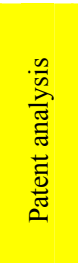 & 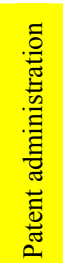 & 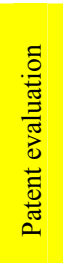 & 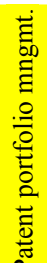 & 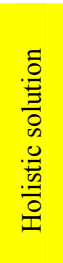 \\
\hline xPD & $\begin{array}{c}\text { SAP AG } \\
\text { www.sap.com }\end{array}$ & & $x$ & $x$ & $x$ & $\mathbf{x}$ & $x$ & & $x$ & $\mathbf{x}$ & $\mathbf{x}$ & & & & & & & $\mathbf{X}$ \\
\hline
\end{tabular}

